\title{
Mitarbeiterinnen und Mitarbeiter dieses Heftes
}

Prof. Ernst Elitz, ehemaliger Intendant des Deutschlandradios.

Prof. Dr. Alexander Filipović, Inhaber des Lehrstuhls für Medienethik an der Hochschule für Philosophie der Jesuiten in München.

Annika Franzetti, Dipl.-Journ., ist Lehrkraft für besondere Aufgaben am Studiengang Journalistik der Katholischen Universität EichstättIngolstadt und Redakteurin von Communicatio Socialis.

Dr. Renate Hackel-de Latour, M. A., ist Akademische Direktorin am Studiengang Journalistik der Katholischen Universität Eichstätt-Ingolstadt und Redakteurin von Communicatio Socialis.

Prof. em. Dr. Joan Hemels, lehrte bis 2009 Kommunikationswissenschaft an der Universität Amsterdam

Michael Kasiske, Dipl.-Theol., Communications Master of Science, ist Pressereferent beim Erzbistum Köln.

Detlef David Kauschke, Chefredakteur der Jüdischen Allgemeinen.

Prof. Dr. Georg Langenhorst, Inhaber des Lehrstuhls für Didaktik des katholischen Religionsunterrichts/Religionspädagogik an der Katholisch-Theologischen Fakultät der Universität Augsburg.

Moritz Povel, B. A., hat Politikwissenschaft und Wirtschaft an der Westfälischen Wilhelms-Universität Münster studiert und war von April 2011 bis April 2013 Volontär in der Gedenkstätte Yad Vashem in Jerusalem. Im Herbst beginnt er ein Masterstudium in Politikwissenschaft in London.

Raphael Rauch, M.A., Stipendiat des internationalen Graduiertenkollegs „Religiöse Kulturen im Europa des 19. und 20. Jahrhunderts“ an der Ludwig-Maximilians-Universität in München. Er studierte Geschichte, Politikwissenschaft und Katholische Theologie in Tübingen, Aix-en-Provence und an der Yale University.

Meike D. Schuster, Dipl.f.Bild.K., ist Bildungswissenschaftlerin und freiberufliche Autorin.

Martin Willebrand, M.A., ist Studienreferendar an einem Gymnasium im Münsterland. Er studierte Katholische Theologie, Germanistik und Erziehungswissenschaften in Münster und Eichstätt. 